\title{
APPLICATIONS OF PSPICE PROGRAM IN CIRCUITRY INVESTIGATION AND AUTOMATION CIRCUIT SIMULATION
}

\section{Pawel BACHMAN - Piotr GAWLOWICZ - Marcin CHCIUK}

\begin{abstract}
The paper presents capabilities of applications PSpice program in circuitry investigation and automation circuit simulation. Next part of the article shows examples of tasks from electrical engineering, electronic and automation with their solutions in PSpice. The final part consist short describe of the other tasks, which are possible to execute in PSpice.
\end{abstract}

Key words: technical education, simulation, PSpice

\section{ZASTOSOWANIE PROGRAMU PSPICE W BADANIU OBWODÓW ELEKTRYCZNYCH ORAZ W SYMULACJI UKLADÓW AUTOMATYKI}

Streszczenie: $W$ artykule opisano możliwości zastosowania programu PSpice w badaniach obwodów elektrycznych i symulacjach układów automatyki. Pokazano też przykłady zadań z elektrotechniki, elektroniki i automatyki oraz ich rozwiązania w PSpice. Końcowa część artykutu zawiera krótki opis innych zadań, jakie można wykonać w PSpice.

Stowa kluczowe: edukacja techniczna, symulacje, PSpice

\section{Wstęp}

Projektowany układ elektryczny lub fizyczny można zasymulować poprzez stworzenie jego modelu w programach komputerowych typu PSpice, Matlab czy VisSim. Dzięki elastyczności wyżej wymienionych programów, niemalże $\mathrm{w}$ dowolny sposób można symulować transmitancje obiektów, dobierać parametry pracy a także czas trwania lub parametry początkowe i końcowe symulacji. Wyniki badań otrzymuje się w bardzo przejrzystej formie graficznej: wykres lub wyświetlenie wartości na schemacie $\mathrm{w}$ postaci cyfrowej. Programy te można wykorzystać nie tylko podczas projektowania różnego rodzaju układów, ale także w procesie dydaktycznym studentów Edukacji Techniczno-Informatycznej, na takich przedmiotach jak elektrotechnika, elektronika a także automatyka. Mogą oni dzięki nim rozwiązywać zadania z zakresu obliczania obwodów elektrycznych, badać kształt przebiegów napięć i prądów oraz symulować działanie różnych obiektów sterowania.

\section{Opis pakietu PSpice}

Program PSpice wywodzi się ze standardu Spice (Simulation Program with Integrated Circuit Emphasis) opracowanego pod koniec lat 60-tych XX w. na Uniwersytecie Berkeley. Od roku 1984 jako wersja komercyjna był rozprowadzany przez firmę MicroSim (do wersji 8.0)[1, 2]. Nowsza wersja 9.0 oferowana była przez firmę Orkad. Obecnie program ten rozprowadzany jest przez firmę Cadence Design Systems (www.cadence.com). W internecie dostępna jest też darmowa wersja edukacyjna dla studentów (Student Version 9.1). Ma ona jednak w stosunku do pełnej wersji pewne ograniczenia. Główne z nich to mniejsza ilość elementów w bibliotekach i ograniczona ilość symboli i węzłów zawartych na jednym analizowanym schemacie.

W skład programu PSpice wchodzą następujące pakiety:

- Schematics - służy do rysowania schematu układu i określania parametrów poszczególnych elementów oraz wybiera się w nim rodzaj i parametry analizy,

- PSpice A/D - pozwala na dokonanie obliczeń do symulacji analogowych i cyfrowych układów elektronicznych,

- Probe - umożliwia analizę oraz obróbkę wyników symulacji w formie graficznej (wykresy),

- PSpice Optimizer - umożliwia optymalizację analogowych układów elektronicznych,

- Parts - tworzy modele elementów na podstawie opisu ich podstawowych parametrów,

- PCBoards - tworzy płytki drukowane na podstawie narysowanego schematu,

- PLSyn - tworzy układ jednoelementowy, zawierający w sobie całą strukturę narysowanego wcześniej schematu, 
- SPECCTRA - jest częścią PCBoards, pozwala na tworzenie płytek drukowanych $\mathrm{w}$ technologi CCT (Cooper \& Chyen Technology).

Elementy, które używa się do symulacji układów elektronicznych to rezystory, kondensatory, cewki, układy scalone analogowe i cyfrowe, diody, tranzystory, wzmacniacze operacyjne, źródła prądu i napięcia niezależne lub sterowane. Istnieje także możliwość definiowania własnych dodatkowych elementów lub modyfikowania istniejących. Oprócz tego wielu producentów (m. in. Toshiba, Fuji, Motorola, National Semiconductor, Analog Devices, Maxim Integrated Circuits, Philips Semiconductor, SGS-Thomson, Harris Semiconductor, Zetex, Burr-Brown Corp, Infineon, Semitronics Corp, Microsemi CorpEpcos, F.W. Bell, Advance Power Technology, Powerex, International Rectifier i inni) oferuje swoje biblioteki dla tego programu. W swoich bibliotekach program PSpice posiada również elementy, dzięki którym możemy symulować układy sterowania automatycznego.

Pakiet PSpice zawiera narzędzia umożliwiające zbudowanie schematu, symulację analogową, cyfrową, optymalizację i wizualizację całego procesu projektowego. W początkowej fazie $\mathrm{w}$ programie Schematics, $\mathrm{z}$ bloków zdefiniowanych w bibliotekach programu, tworzy się schemat projektu i ustala wartości elementów oraz parametry symulacji. W prosty sposób metodą „weź i puść” wybiera się potrzebne elementy $\mathrm{z}$ biblioteki programu i umieszcza na schemacie. Po umieszczeniu na schemacie wszystkich potrzebnych bloków przy pomocy specjalnego narzędzia rysuje się „ścieżki”, łącząc ze sobą odpowiednie końcówki elementów. Kolejną rzeczą jest wybranie odpowiedniego rodzaju symulacji i ustawienie jej parametrów. Do wyboru są między innymi analizy stało i zmienno prądowe, czasowe i parametryczne.

Następnie uruchamiany jest moduł Probe, który tworzy listę połączeń i sprawdza jej poprawność, a następnie wizualizuje przebiegi napięć lub prądów w układzie. Probe pozwala również wykreślić wyrażenia obliczone przy użyciu funkcji arytmetycznych lub innych funkcji specjalnych. Jeżeli w schemacie lub w opcjach symulacji występują błędy (np. nie został podany jakiś parametr lub jeden $\mathrm{z}$ elementów nie jest podłączony) program sygnalizuje taki błąd i podpowiada jak go usunąć. Jeżeli nie ma błędów wykonywane są obliczenia, które następnie przedstawiane są w formie wykresów. Wykres może pokazywać prąd w obwodzie, napięcie na wybranym elemencie, częstotliwość lub inne wartości elektryczne (skuteczne, zespolone).

Schemat układu można skopiować jedynie w formie bitmapy. Wykres natomiast można przenieść jako metaplik. Proste i wygodnie jest drukowanie wykresów wprost z programu Probe, gdyż program sam dodaje do wykresu nazwę, datę $i$ godzinę wykonania wydruku oraz automatyczne dopasowuje wydruk do rozmiaru papieru. Schemat układu można też wydrukować wraz z wybraną przez siebie z biblioteki tabelką.

\section{Przykladowe zadania wykonane w programie PSpice}

Zadanie I. Sprawdzanie prawa Ohma (rys. 1)

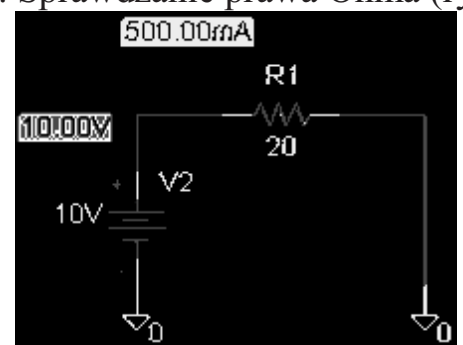

Rys. 1. Schemat do sprawdzania prawa Ohma Rozwiązanie: $\mathrm{I}=\frac{\mathrm{U}}{\mathrm{R}} ; \mathrm{I}=\frac{10[\mathrm{~V}]}{20[\Omega]}=0,5[\mathrm{~A}]$

Zadanie II. Sprawdzanie I prawa Kirchhoffa

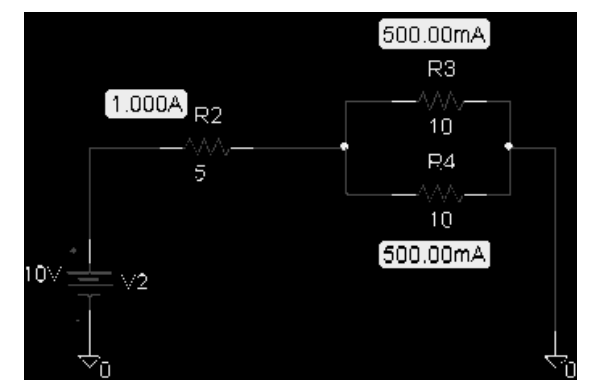

Rys. 2. Sprawdzanie I prawa Kirchhoffa

Rozwiązanie:

$\mathrm{I}_{\mathrm{R} 2}=\mathrm{I}_{\mathrm{R} 3}+\mathrm{I}_{\mathrm{R} 4} ; \mathrm{I}_{\mathrm{R} 2}=1[\mathrm{~A}] ; \mathrm{I}_{\mathrm{R} 3}=\mathrm{I}_{\mathrm{R} 4}=0,5[\mathrm{~A}]$

Zadanie III. Sprawdzanie II prawa Kirchhoffa

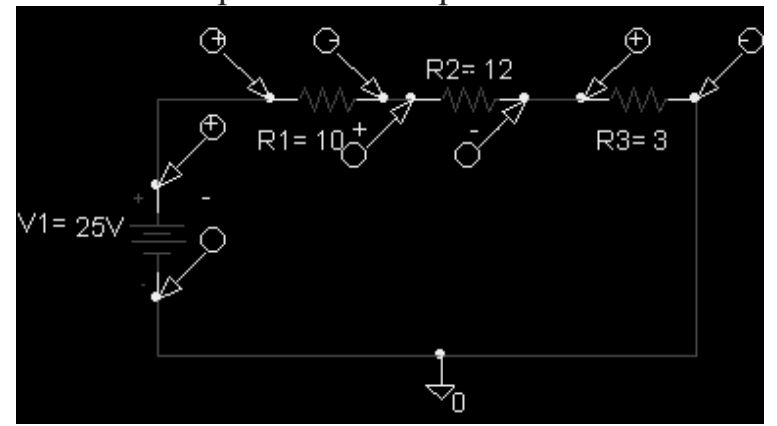

Rys. 3. Schemat do sprawdzania II prawa Kirchhoffa 
Rozwiązanie: $\mathrm{U}_{\mathrm{V} 1}-\mathrm{U}_{\mathrm{R} 1}-\mathrm{U}_{\mathrm{R} 2}-\mathrm{U}_{\mathrm{R} 3}=0$

$$
\mathrm{U}_{\mathrm{R} 1}=10 \mathrm{~V} ; \mathrm{U}_{\mathrm{R} 2}=12 \mathrm{~V} ; \mathrm{U}_{\mathrm{R} 3}=3 \mathrm{~V} \text {; }
$$

Zadanie IV. Badanie napięcia na prostowniku jedno-połówkowym (rys. 4)

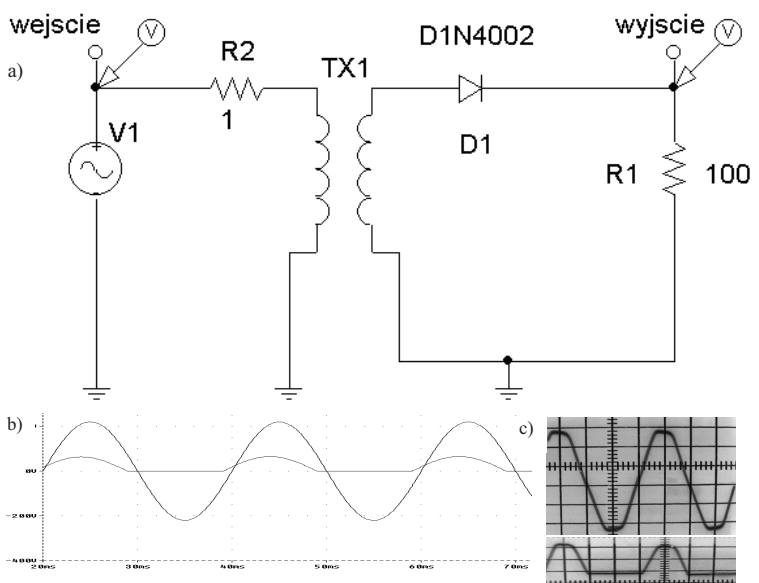

Rys. 4. Schemat prostownika jednopołówkowego

(a) $i$ charakterystyki napięcia wejściowego $i$

wyjściowego uzyskane: w programie PSpice (b); z oscyloskopu podczas badania uktadu rzeczywistego (c)

Zadanie V. Zadanie tekstowe $\mathrm{z}$ zakresu obliczania prądów i napięć w obwodzie (rys. 5)

Prądnica samochodowa, której siła elektromotoryczna $\quad \mathrm{E}_{1}=14 \mathrm{~V} \quad \mathrm{i}$ rezystancja wewnętrzna $\mathrm{Rw}_{1}=0,2 \Omega$ ładuje akumulator o sile elektromotorycznej $\quad E_{2}=12 \mathrm{~V} \quad \mathrm{i}$ rezystancji wewnętrznej $\mathrm{Rw}_{2}=0,1 \Omega$ oraz zasila odbiorniki o rezystancji zastępczej $R_{z}=5 \Omega$. Narysuj schemat układu i oblicz prąd prądnicy $I_{R w 1}$, ładowania akumulatora $\mathrm{I}_{\mathrm{Rw} 2}$ oraz odbiorników $\mathrm{I}_{\mathrm{Rz}}$.

Studenci na ćwiczeniach rachunkowych rozwiązują zadania z zakresu obliczania prądów i napięć w obwodach. Prawidłowość wyników mogą zweryfikować tworząc układ z zadania w programie PSpice i wykonując symulację [5].

$\begin{array}{llll}\mathrm{Rw}_{1} & & \mathrm{Rw}_{2} & \\ & & & \mathrm{R}_{\mathrm{z}} \\ & \mathrm{E}_{1} & \mathrm{E}_{2} & \end{array}$

\section{Rys. 5. Schemat do zadania tekstowego $\mathrm{nr} 6$}

Rozwiązanie: $\mathrm{I}_{\mathrm{Rw1}}=7,5[\mathrm{~A}] ; \mathrm{I}_{\mathrm{Rw} 2}=5[\mathrm{~A}] ; \mathrm{I}_{\mathrm{Rz}}=2,5[\mathrm{~A}]$

Zadanie VI. Badanie odpowiedzi skokowej liniowego modelu serwomechanizmu elektrohydraulicznego 5 rzędu z regulatorem PID

Wartością mierzoną w układzie (rys. 6) jest napięcie, należy jednak pamiętać, że symulowany układ jest to schemat blokowy serwomechanizmu elektrohydraulicznego, w którym w miejscu podłączenia woltomierza występuje przesunięcie liniowe. W związku z tym na wykresie (rys. 7) należało zmienić jednostki na osi $\mathrm{Y}$ z $[\mathrm{mV}]$ na $[\mathrm{m}]$.

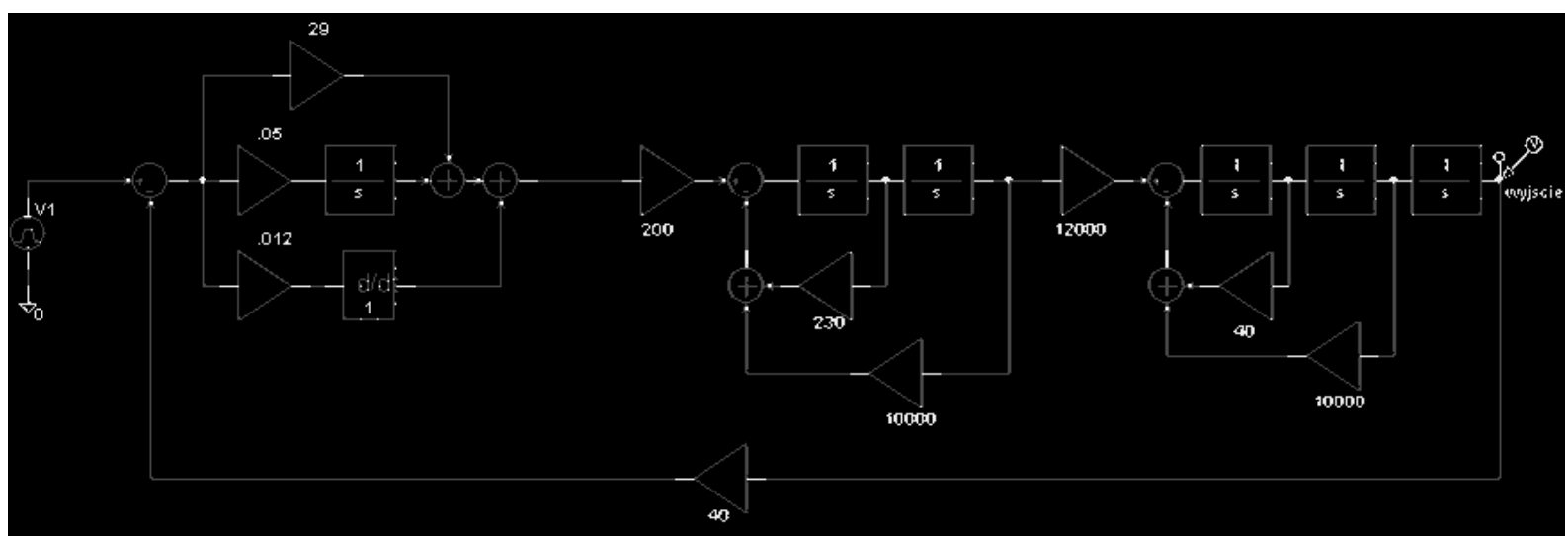

Rys. 6. Schemat liniowego serwomechanizmu elektrohydraulicznego 5 rzędu z regulatorem PID wykonany w programie PSpice [3] 


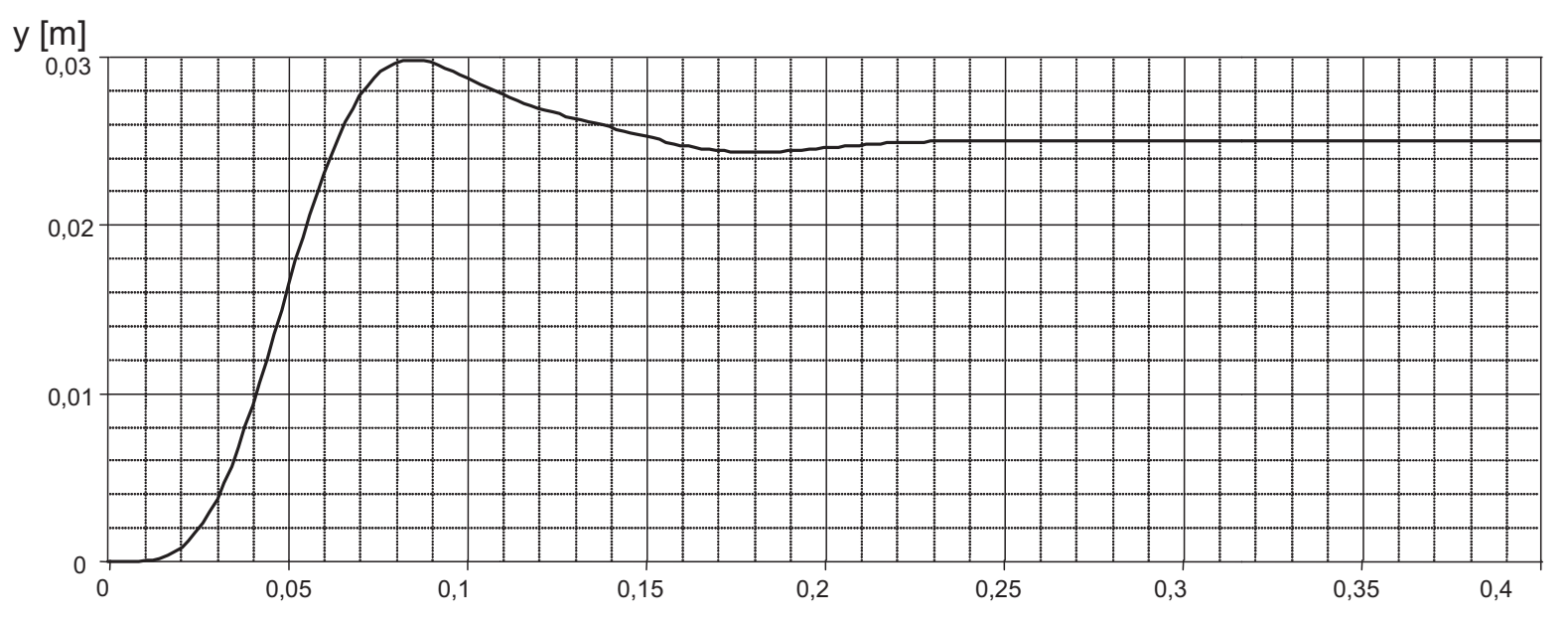

Rys. 7. Odpowiedź układu na skok jednostkowy uzyskana z symulacji

$\mathrm{t}[\mathrm{s}]$ w programie PSpice [4]

\section{Zakończenie}

Przytoczone przykłady pokazują, jak duże możliwości wykorzystania w procesie dydaktycznym daje program PSpice. Wykresy uzyskane w wyniku symulacji niczym nie różnią się od charakterystyk rzeczywistych układów (rys. 4). Można dzięki niemu badać również inne zjawiska elektryczne: np. rezonans równoległy, szeregowy, ładowanie i rozładowanie kondensatora, a także projektować i sprawdzać filtry oraz badać odpowiedzi skokowe podstawowych członów automatyki. $\mathrm{Na}$ podstawie uzyskanych wykresów można wykonać analizę wyników symulacji wybierając konkretne punkty i odczytując ich dane lub przeprowadzając np. rozkład Fouriera.

\section{Bibliografia}

[1] IZYDORCZYK, J. PSpice komputerowa symulacja układów elektronicznych. 1993, Gliwice, Wydawnictwo Helion. ISBN 83-8570107-9.

[2] KRÓL, A., MOCZKO, J. PSpice symulacja i optymalizacja układów elektronicznych. 1998, Poznań, Wydawnictwo Nakom. ISBN: 83-8696928-8.
[3] MILECKI, A. Liniowe serwonapędy elektrohydrauliczne. Modelowanie i sterowanie. Wydawnictwo Politechniki Poznańskiej. 2003, Poznań. ISBN 83-7143-493-6.

[4] BACHMAN, P. Możliwości zastosowania programów PSpice i VisSim do symulacji układów serwonapędów elektrohydraulicznych. Hydraulika i Pneumatyka. 2005, Wrocław, nr 1, s. 7 -11. ISSN 1505-3954.

[5] ZACHARA Z., WOJTUSZKIEWICZ K., PSpice. Przykłady praktyczne. 2000, Warszawa, Wydawnictwo MIKOM. ISBN:83-7279-076-0.

mgr inż. Paweł Bachman,

P.Bachman@eti.uz.zgora.pl

dr inż. Piotr Gawłowicz,

P.Gawlowicz@eti.uz.zgora.pl mgr Marcin Chciuk, M.Chciuk@eti.uz.zgora.pl

Uniwersytet Zielonogórski

Instytut Edukacji Techniczno-Informatycznej

ul. prof. Szafrana 4

65 - 516 Zielona Góra 